\title{
ЭФФЕКТИВНАЯ ОРГАНИЗАЦИЯ ВНУТРЕННЕГО КОНТРОЛЯ НА ПРОМЬШЛЕННОМ ПРЕДПРИЯТИИ - ЗАЛОГ ФИНАНСОВОЙ УСТОЙЧИВОСТИ И СТАБИЛЬНОСТИ ПРЕДПРИЯТИЯ
}

\section{EFFECTIVE ORGANIZATION OF INTERNAL CONTROL AT AN INDUSTRIAL ENTERPRISE IS THE KEY TO FINANCIAL STABILITY AND ENTERPRISE STABILITY}

M. Starkova

A. Klonitskaya

Summary. The problem of effective organization of internal control has acquired particular significance in connection with the role that control began to play at the present stage in ensuring a stable, stable and profitable operation of an industrial enterprise.

It was noted that the effective organization of internal control is possible only under the condition of an integrated approach, which implies the existence of a concept, model, documents on performance evaluation and control procedures.

The article emphasizes that for an effective internal organization, it is necessary to implement three stages, where the first specifies the characteristics and elements of the internal control system, the second is the formation of the control service and the third is the development of the Model Provision on the internal control service.

It was concluded that the successful organization of internal control in an industrial enterprise is the key to its financial stability and development.

Keywords: internal control, industrial enterprise, concept, model, Model position.

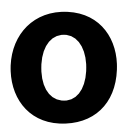
щутимый вклад в разрешение теоретических и методологических проблем организации внутреннего контроля внесли такие отечественные исследователи, как В.В. Бурцев, Т.В. Каковкина, А. В. Порфирьева, Т.Ю. Серебрякова и другие ученые. Но пока не все еще аспекты данной проблемы нашли разрешение и это относится к оценке влияния внутреннего контроля на устойчивость и стабильность промышленного предприятия.

В связи с этим цель данной статьи заключается в постановке и рассмотрении вопросов эффективной орга-
Старкова Мария Михайловна

К.э.н., доцент, Московский авиационный институт (национального исследовательского университета) starkova_maria@mail.ru

Клоницкая Анна Юрьевна

К.э.н., доцент, Московский авиационный институт (национального исследовательского университета) anna_klonitskaya@mail.ru

Аннотация. Проблема эффективной организации внутреннего контроля приобрела особую значимость в связи с той ролью, которую контроль стал играть на современном этапе в обеспечении устойчиво-стабильной и прибыльной работы промышленного предприятия.

Отмечено, что эффективная организация внутреннего контроля возможна только при условии комплексного подхода, предполагающего наличие концепции, модели, документов по оценке эффективности и проведению процедур контроля.

В статье подчеркивается, что для эффективной организации внутреннего контроля необходима реализация трех этапов, где на первом этапе уточняются характеристика и элементы системы внутреннего контроля, на втором — осуществляется формирование службы контроля и на третьем разработка Типового положения о службе внутреннего контроля.

Сделан вывод о том, что успешная организация внутреннего контроля на промышленном предприятии является залогом его финансовой устойчивости и стабильности развития.

Ключевые слова: внутренний контроль, промышленное предприятие, концепция, модель, Типовое положение.

низации внутреннего контроля на промышленном предприятии, влияющего на его устойчивое развитие.

Взаимосвязь внутреннего контроля и стабильного развития предприятия проявляется через достоверность отчетной информации, выявление рисков, их минимизации и нивелирование.

Вопрос обязательного формирования и организации контроля возник на повестке дня предприятий и организаций после принятия новой редакции Федерального закона «О бухгалтерском учете», где в ст. 19 зафиксиро- 
вано, что любой из экономических субъектов обязан организовывать и осуществлять внутренний контроль совершаемых фактов хозяйственной жизни.[1]

Надо признать, что зачастую, на промышленном предприятии распространено формальное отношение к созданию службы и организации внутреннего контроля, которое заключается, прежде всего, в документальном оформлении требуемых инструкций и положений, не позволяющем признать в целом успешными попытки создания системы внутреннего контроля.

Чтобы создать эффективную и действительно работающую службу внутреннего контроля, дающую возможность финансовой и стабильной работы, следует заранее знать и готовиться к тому, что ее создание и постановка системы внутреннего контроля - это длительный и трудоемкий процесс, предполагающий проведение следующих мероприятий:

- детальное ознакомление как с действующей в России, так и зарубежной нормативно-правовой документацией по организации внутреннего контроля;

- проведение тщательного и эффективного анализа деятельности промышленного предприятия и его структурных подразделений;

- разработку внутренних нормативных документов по организации системы внутреннего контроля на предприятии в рамках действующих нормативных документов;

- выработку и постановку цели формируемой системы внутреннего контроля и оценку возможностей ее достижения;

- построение механизма взаимосвязи структурных и функциональных подразделений промышленного предприятия (отделов, цехов, служб, бизнес-процессов и т.п.) при формировании системы внутреннего контроля;

- подготовку персонала к организации системы внутреннего контроля на промышленном предприятии;

- планирование мероприятий по созданию службы внутреннего контроля [7, с. 37-42].

Как представляется авторам статьи, для успешной реализации внутреннего контроля необходим комплексный подход, предполагающий постановку проблем и предложения по их разрешению в виде методических разработок.

В числе проблем - концептуальное видение внутреннего контроля, включающее трактовку, принципы, цель, задачи, методы и элементы контроля, моделирование, оценку эффективности и процедурные аспекты внутреннего контроля.
В связи с этим авторы посчитали необходимым предложить следующий алгоритм практической организации системы внутреннего контроля на промышленном предприятии, представляющий собой как поэтапное, так и параллельно-горизонтальное проведение определенных мер и мероприятий в увязке с этапами.

Этапы организации внутреннего контроля могут включать:

- на первом этапе характеристику и уточнение элементов системы внутреннего контроля объект внутреннего контроля, предмет внутреннего контроля, субъекты внутреннего контроля, контрольную среду, проиедуры внутреннего контроля; информационное обеспечение и коммуникации, оценку рисков и оценку системы внутреннего контроля, необходимых для формирования службы, подготовки нормативно-правовой документации;

- на втором этапе формирование отдела (службы) внутреннего контроля в рамках соответствующей организационной структуры промышленного предприятия или переформатирование имеющихся отделов контроля с учетом специфики системы внутреннего контроля;

- на третьем этапе разработку Типового положения о внутреннем контроле (службе внутреннего контроля), включающего шесть разделов (возможно с дополнительным разделом «Направления деятельности, требующие дополнительного контроля»), а также приложений.

Параллельно-горизонтальные меры и мероприятия предполагают:

- на первом этапе - раскрытие и подробное описание инструментария (методов и способов контроля), элементов системы внутреннего контроля, прежде всего, таких как контрольная среда и процедуры внутреннего контроля;

- на втором этапе - уточнение в зависимости от элементов внутреннего контроля количественного состава, должностных обязанностей создаваемого подразделения, а также составление должностных инструкций, построение схемы взаимоотношений с другими структурными подразделениями.

Наиболее крупные меры и мероприятия предполагаются на третьем этапе и могут включать в себя:

- составление плана проведения плановых проверок;

- наброски возможных внеплановых проверок;

- разработку перечня процедур и методов, применяемых при проверках; 
1 -ый этап -

раскрытие и

подробная

характеристика

элементов ВК

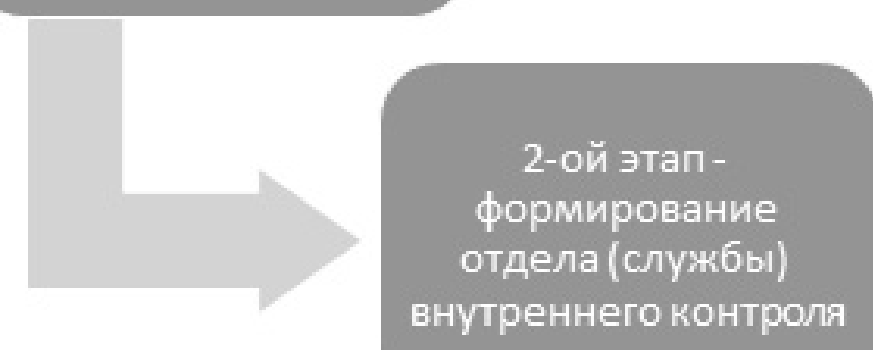

внутреннего контроля

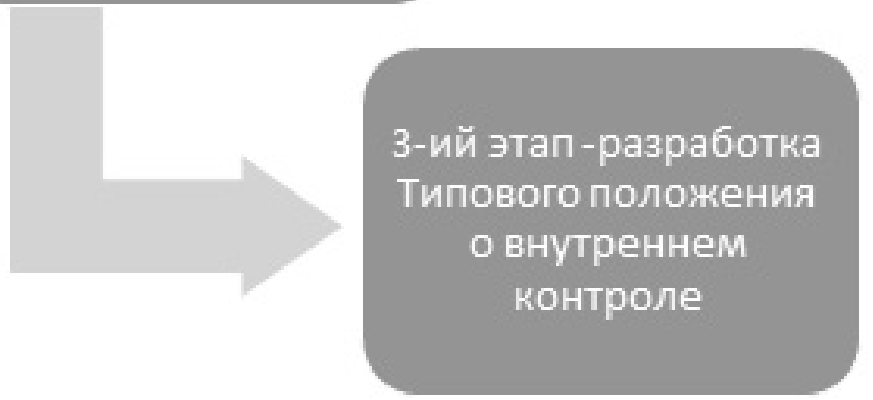

Рис. 1. Этапы организации внутреннего контроля на промышленном предприятии

- составление перечня «Направления деятельности, требующие дополнительного контроля».

Описанные этапы алгоритма практической реализации внутреннего контроля представлены автором в виде схемы на рис. 1.

Типовое положение о Службе внутреннего контроля должно включать, как представляется, следующие составные части:

\section{Содержание}

1. Общие положения, касающиеся деятельности службы внутреннего контроля

2. Задачи, функции и принципы организации и функционирования Службы внутреннего контроля

3. Взаимоотношения Службы внутреннего контроля с другими структурными подразделениями промышленного предприятия

4. Порядок и методы организации проверок и отражения результатов проверок

5. Права и обязанности сотрудников и руководителя Службы внутреннего контроля

6. Заключительные положения
Приложение 1. Квалификационные требования к руководителю Службы внутреннего контроля (разрабатываются конкретным предприятием)

Приложение 2. Схема взаимоотношений Службы внутреннего контроля и других структурных подразделений (разрабатывается конкретным предприятием).

Приложение 3. Методика разработки процедур внутреннего контроля

Приложение 4. Механизм оценки операционной эффективности системы внутреннего контроля

Приложение 5. Модель внутреннего контроля

Рациональная организация внутреннего контроля и методико-практические подходы к построению эффективной системы внутреннего контроля предполагают не только создание Типового положения, но и формирование эффективной организационной структуры, вписываемой в структуру промышленного предприятия, написание регламентов, отражение порядка внутреннего контроля в Уставе и т.д.

Следовательно, на промышленном предприятии для его устойчивого и стабильного развития должны существовать: 
- Устав промышленного предприятия, в котором отражена работа системы внутреннего контроля;

- Схема и описание организационной структуры управления предприятия с указанием имеющихся контрольных подразделений.

Считаем, что для осуществления функций внутреннего контроля в полном объеме на промышленном предприятии следует создавать именно службу (отдел) внутреннего контроля в общей структуре управления, а не замещающие его группы финансового контроля, отделы внутреннего аудита и т.п. В уставе промышленного предприятия необходимо отразить организационную структуру с включением службы внутреннего контроля.

- Положение об отделе (службе, управлении, Департаменте), осуществляющем функции внутреннего контроля (аудита);

- Регламент осуществления контрольной деятельности. Регламент контрольной деятельности на предприятии может существовать отдельно или дополнительно к Положению о службе внутреннего контроля

В данном регламенте указывается цель осуществления контрольной деятельности, а именно порядок проведения проверок, выявление, предупреждение критических отклонений в выполнении текущих финансовых задач и предотвращение нарушений финансово-хозяйственной деятельности. Приводится также порядок организации планирования контрольной деятельности с указанием плановых и внеплановых проверок, комплекс контрольных действий, среди которых поступления и расходования средств. Предлагается также включение раздела в Положение о системе внутреннего контроля- «Направления деятельности, требующие дополнительного контроля».

Модель организации системы внутреннего контроля включает формирование бизнес-процессов и центров финансовой ответственности с идентификацией рисков и проблемных зон по бизнес-процессам и постановкой внутреннего контроля именно по бизнес-процессам и центрам финансовой ответственности (ЦФО) в условиях влияния факторов внутренней и внешней среды.

Следовательно, основными компонентами модели внутреннего контроля являются:

1. Контроль по основным и вспомогательным бизнес-процессам

2. Контроль по ЦФО - центрам затрат и прибыли

3. Учет при контроле факторов внутренней и внешней среды, влияющих на деятельность промышленного предприятия

4. Учет при контроле рисков деятельности.
Целевая функция модели внутреннего контроля состоит в реализации контрольных мероприятий по бизнес-процессам и центрам затрат и прибыли, направленных на эффективное использование ресурсов и выявление резервов. К функциям модели внутреннего контроля относится контроль как позитивных факторов, направленных на снижение затрат и рост прибыли, так и негативных факторов внутренней и внешней среды, ведущих к рискам функционирования.

Входная информация модели представляет собой информационное обеспечение (внутреннее и внешнее) для удовлетворения потребностей как внутренних, так и внешних пользователей информации. Самыми значимыми источниками для характеристики деятельности выступает бухгалтерская (финансовая) отчетность, а также экономическая информация управленческого учета, представляющая совокупность данных о состоянии внутренней среды и факторах влияния внешней среды и являющаяся важнейшим связующим элементом для решения определенных управленческих задач.

Выходной информацией модели выступает контролируемая и достоверная информация, а также мероприятия по минимизации негативных позиций и повышению достоверности, представляемые руководству и заинтересованным лицам.

Участие в модели внутреннего контроля, как бизнес-процессов, так и центров финансовой ответственности предполагает использование матрицы функциональных подразделений и бизнес-процессов, когда объединяется функциональное и процессное управление.

В матрице по вертикали приводятся функциональные отделы - центры затрат и прибыли, а по горизонтали - бизнес-процессы и субпроцессы, отражающие деятельность данного функционального подразделения и по которым осуществляется внутренний контроль.

В условиях функционирования управленческого учета и системы внутреннего контроля центры финансовой ответственности являются также объектами бюджетирования, входящего в систему управленческого учета и позволяющего осуществлять эффективный контроль путем передачи ответственности отдельным структурным подразде лениям; проводить оперативный анализ результа тов с выделением проблемных участков и зон; предоставлять информацию руководству об участках, где не достигнуты планируемые показатели.

Следующими компонентами модели внутреннего контроля являются факторы внутренней и внешней среды, раскрываемые в модели с использованием SWOT- 
анализа, а также риски, контроль которых, в широком понимании, в модели внутреннего контроля можно представить, как поступательный процесс их трех этапов, где:

- на первом этапе происходит описание рисков, включающее идентификацию и классификацию рисков, связанных с хозяйственной деятельно стью промышленного предприятия;

- на втором этапе осуществляется оценка выявленного риска;
- на третьем этапе принимаются решения по снижению уровня риска.

Резюмируя, заметим, что приводимая схема организации внутреннего контроля позволит промышленным предприятиям за счет получения достоверной отчетной информации, выявления узких проблемных мест, минимизации и нивелирования рисков повысить эффективность деятельности и стать более финансово устойчивыми и стабильными.

\section{ЛИТЕРАТУРА.}

1. Федеральный закон № 402-Ф3 от 06.12.2011 «0 бухгалтерском учете», ст. 19 Внутренний контроль (в ред. от 28.11.2018)

2. Информация Минфина России № П3-11/2013 «0рганизация и осуществление экономическим субъектом внутреннего контроля совершаемых фактов хозяйственной жизни, ведения бухгалтерского учета и составления бухгалтерской (финансовой) отчетности» [Электронный ресурс]: Доступ из справочно правовой системы «Консультант Плюс».

3. Доклад «Внутренний контроль: интегрированный подход» (COSO), подготовленный Комитетом спонсорских организаций Комиссии Тридуэя (the Committee of Sponsoring Organizations of the Treadway Commission's Internal control — Integrated Framework), Compliance: URL: http://www.coso.org/documents/ COS0\%20McNallyTransition\%20Article-inal\%20C0S0\%20Version\%20Proof_5-31-13.pdf.

4. Концепция $\operatorname{COSO}$ «Управление рисками организации. Интеграция со стратегией и эффективностью деятельности. М., ИВА, 2017.—150с

5. Богданович И.С., Соболева О. А. Место внутреннего контроля в системе управления предприятием и форма его организации / И. С. Богданович, 0. А. Соболева // Вестник Псковского государственного университета. Серия: Экономика. Право. Управление. — 2014. -№ 5.

6. Бурцев В. В. Организация системы государственного финансового контроля в Российской Федерации: теория и практика. М: Дашков и К. 2005.

7. Каковкина Т. В. Система внутреннего контроля как средство выявления рисков организации //Международный бухгалтерский учет -2014- № 36(330).— C. $37-42$

8. Книзберг Ю. Н. Место внутреннего контроля в системе управления //Российское предпринимательство.— 2008 — № 3(107).

9. Пашков Р.В., Юденков Ю. Н. Внутренний контроль в публичном секторе. Монография. М., РУСАЙНС, 2016.

10. Пашков Р.В., Юденков Ю. Н., Российские модели внутреннего контроля. /Бухгалтерия и банки. — 2016 — № 3.

11. Порфирьева А.В., Серебрякова Т. Ю. Внутренний контроль: методология сквозного контроля автономных учреждений. Монография. М., Инфра-М, 2016.

12. Серебрякова Т. Ю. Теория и методология сквозного внутреннего контроля. Монография. М. Инфра-М, 2016. 328с.

13. Чайковская Л. А. Информационное обеспечение внутреннего контроля / Л. А. Чайковская// Сборник тезисов докладов Международной научно-практической конференции «Модернизация экономических систем: взгляд в будущее», Прага, Чешская Республика (6 ноября 2015).

14. Чайковская Л. А. Эффективный внутренний контроль и факторы, оказывающие на него влияние / Л.А Чайковская// Аудит и финансовый анализ М.: 2016 (февраль).—№ 1.

15. Лютер Е.В., Гусарова Ю. В., Старкова М. М., Клоницкая А. Ю. Анализ и оценка результатов финансово-хозяйственной деятельности для минимизации нало говых рисков организаций. — Журнал «Эффективное антикризисное управление». 2016. — № 3 (96).

16. Старкова М.М., Лошакова А. А. Заемные средства как инструмент эффективного функционирования и развития промышленного предприятия // Современная наука: актуальные проблемы теории и практики. Серия «Экономика и право»,—2019, -№ 8, -С.36-40

(c) Старкова Мария Михайловна ( starkova_maria@mail.ru ), Клоницкая Анна Юрьевна ( anna_klonitskaya@mail.ru ).

Журнал «Современная наука: актуальные проблемы теории и практики» 